\title{
I-Shape Electromagnetic Band Gap Structure Loaded Microstrip Array Antenna
}

\author{
K. Prahlada Rao ${ }^{1}$, Vani R.M ${ }^{2}$, P.V. Hunagund ${ }^{3}$ \\ Research Scholar, Dept of PG Studies and Research in Applied Electronics, Gulbarga University, Gulbarga, India ${ }^{1}$ \\ Professor and Head, University Science Instrumentation Centre, Gulbarga University, Gulbarga, India ${ }^{2}$ \\ Professor, Department of PG Studies and Research in Applied Electronics, Gulbarga University, Gulbarga, India ${ }^{3}$
}

\begin{abstract}
This article demonstrates the performance enhancement of a simple and low cost four element array antenna by loading the electromagnetic band gap (EBG) structure in the ground plane. The paper discusses the alleviation of mutual coupling between the array elements is also observed. The distance between the adjacent array elements is maintained as $\lambda / 4$ at the design frequency of $6 \mathrm{GHz}$. Initially the conventional four element array antenna is designed. The modified array antenna shows improved performance in terms of miniaturization, bandwidth, mutual coupling and radiation properties. It is resonating at three frequencies and a virtual size reduction of $30.01 \%$ is obtained. The array antenna designed possesses directional radiation properties. Mentor Graphics IE3D simulation software is used to design the antennas and measured results are obtained using vector network analyzer.
\end{abstract}

Keywords: Array antenna, Bandwidth, Periodic structure, Surface waves.

\section{INTRODUCTION}

Due to decrease in the size of the active and passive communication devices, there is a huge demand for the design of compact antennas. Microstrip patch antennas came into existence in the year 1971 and have replaced various antennas in variety of applications because of their advantages and superior performance. Since then extensive research is being carried out by exploiting the various features of these antennas. However, they suffer from few limitations like narrow bandwidth and high mutual coupling between the array elements. [1-4]. The limitations of microstrip antennas and arrays can be overcome to a certain extent by using periodic structures. EBG structures fall under the category of periodic structures. The high value of mutual coupling is due to the emission of surface waves at the dielectric substrate. Surface waves pose serious threat to the performance of microstrip antennas and arrays. These waves restrict the frequency range of operation of the antennas. They reduce the antenna efficiency, gain, output power level and limit the bandwidth. Moreover, they increase end fire radiation and cross polarization levels. EBG structures are capable of improving the performance characteristics of microstrip array antenna. EBG structures allow or forbid the propagation of electromagnetic waves over certain frequency ranges. These bands of frequencies are called as band gaps. [5-14]

\section{CONVENTIONAL ARRAY ANTENNA CONFIGURATION}

The conventional array antenna (CAA) designed consists of four identical radiating patches placed adjacent to each other. The radiating patch used is of rectangular shape. The design frequency of CAA is $6 \mathrm{GHz}$. The schematic of CAA is depicted in Fig.1.

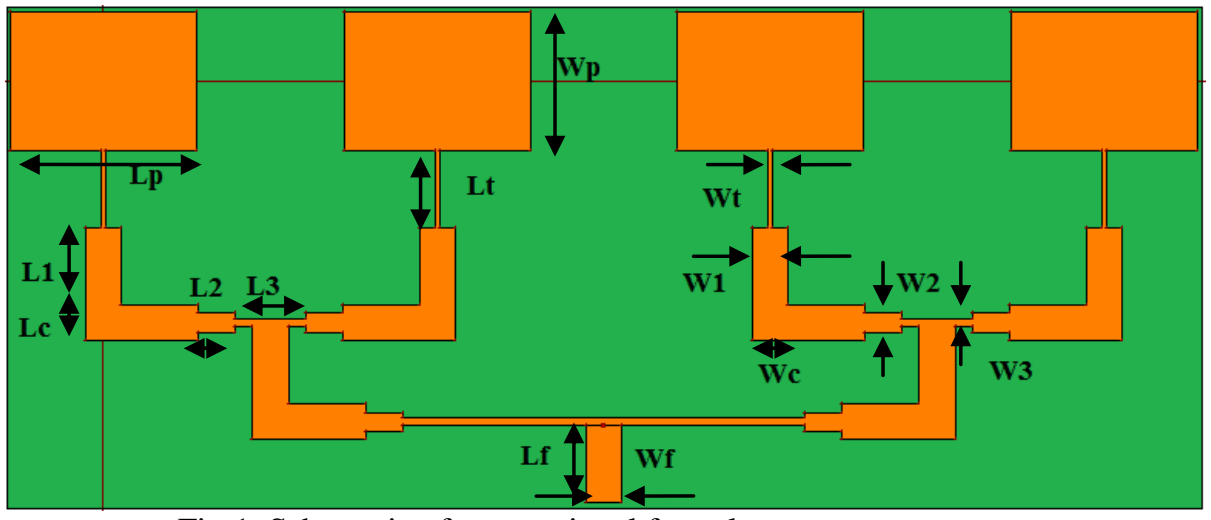

Fig.1. Schematic of conventional four element array antenna. 
Here, corporate feeding technique is used to feed the CAA. In this feeding technique three transmission lines of impedances 50, 70 and $100 \Omega$ are employed. The array antennas designed have been fabricated with height $1.6 \mathrm{~mm}$ and using FR-4 glass epoxy substrate with dielectric constant of 4.2. The distance between the adjacent radiating patches (edge to edge) of CAA is equal to $\lambda / 4$, where $\lambda$ is the wavelength calculated at the design frequency of $6 \mathrm{GHz}$. The dimensions of CAA are summarized in Table 1.

Table 1. Parameter values of conventional four element array antenna.

\begin{tabular}{|l|c|}
\hline \multicolumn{1}{|c|}{ Parameter } & Value(mm) \\
\hline Length of the patch (Lp) & 15.73 \\
\hline Width of the patch (Wp) & 11.76 \\
\hline Length of the quarter wave transformer (Lt) & 6.47 \\
\hline Width of the quarter wave transformer (Wt) & 0.47 \\
\hline Length of the $50 \Omega$ line (L1) & 6.52 \\
\hline Width of the $50 \Omega$ line (W1) & 3.05 \\
\hline Length of the coupler & 3.05 \\
\hline Width of the coupler & 3.05 \\
\hline Length of the $70 \Omega$ line (L2) & 6.54 \\
\hline Width of the $70 \Omega$ line (W2) & 1.62 \\
\hline Length of the $100 \Omega$ line (L3) & 6.56 \\
\hline Width of the $100 \Omega$ line (W3) & 0.70 \\
\hline Length of the feed line (Lf) & 6.52 \\
\hline Width of the feed line (Wf) & 3.05 \\
\hline
\end{tabular}

Mutual coupling is a very important parameter that decides the antenna performance. In order to measure mutual coupling between the array elements, the four radiating patches are fed independently as shown in Fig.2, assuming all the four antennas of the array are equally fed.

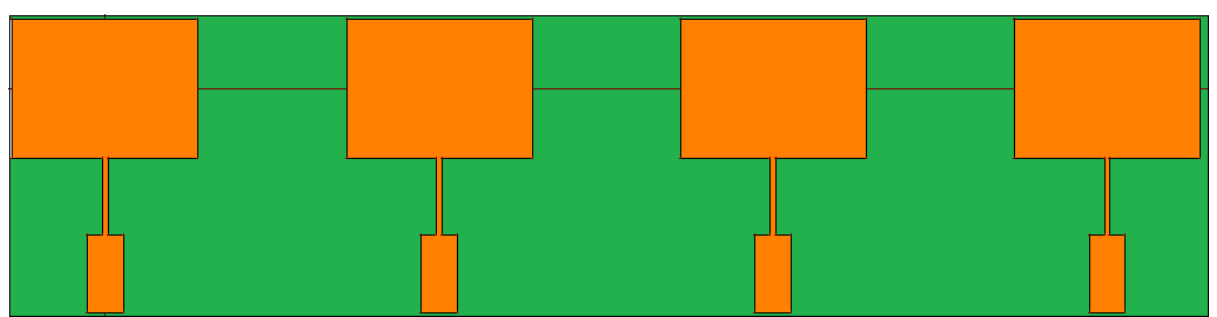

Fig.2.Schematic of four element conventional array antenna for the measurement of mutual coupling

The measured results of CAA have been obtained using vector network analyzer and are depicted in Figs. 3, 4 and 5 respectively. The figures depict the plots of return loss and mutual coupling versus frequency. The frequency range selected is $1-7 \mathrm{GHz}$. The return loss is designated by the $\mathrm{S}$-parameter $\mathrm{S}_{11}$ and mutual coupling by the $\mathrm{S}$-parameters $\mathrm{S}_{21}, \mathrm{~S}_{31}$ and $\mathrm{S}_{41}$ respectively.

From Figs 3, 4 and 5 we see that the array antenna CAA is resonating at a fundamental frequency of $5.53 \mathrm{GHz}$ with a return loss of $-21.06 \mathrm{~dB}$. The measured bandwidth $\left(\mathrm{S}_{11}=-10 \mathrm{~dB}\right)$ achieved is equal to $273 \mathrm{MHz}$.

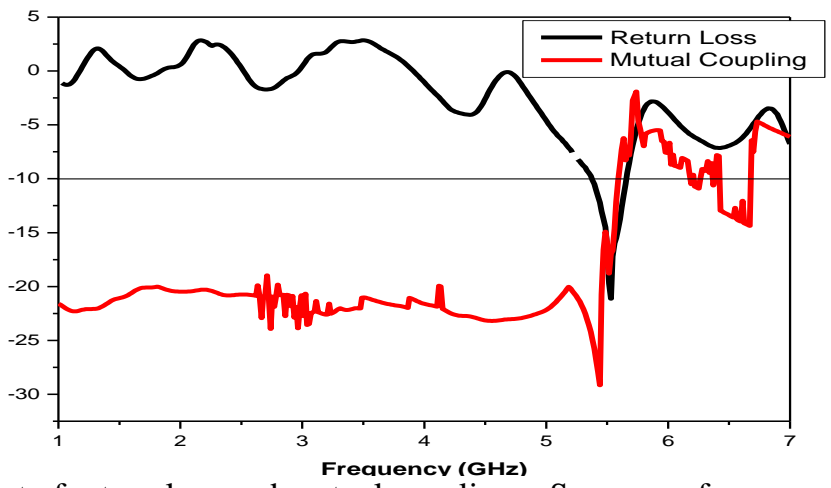

Fig.3. Plot of return loss and mutual coupling $-S_{21}$ versus frequency of CAA. 
UGC Approved Journal

IJIREEICE

\section{International Journal of Innovative Research in} Electrical, Electronics, Instrumentation and Control Engineering

\section{ISO 3297:2007 Certified}

Vol. 5, Issue 6, June 2017

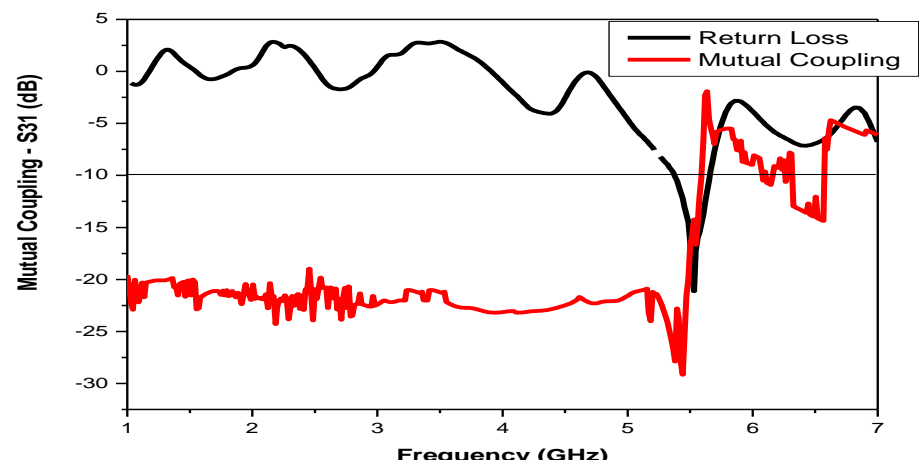

Fig.4. Plot of return loss and mutual coupling $-\mathrm{S}_{31}$ versus frequency of CAA..

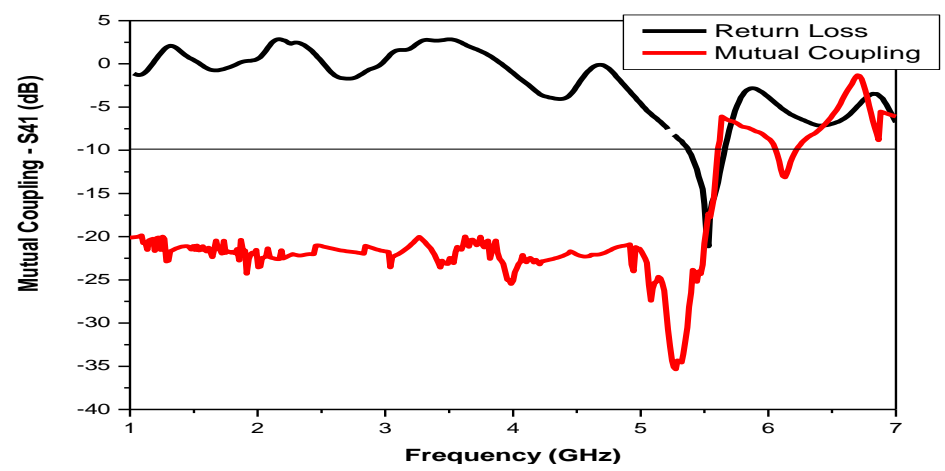

Fig.5. Plot of return loss and mutual coupling $-\mathrm{S}_{41}$ versus frequency of CAA.

From Figs. 3, 4 and 5 we also see that the return loss and mutual coupling plots are overlapping at the frequency of 5.53 $\mathrm{GHz}$. This means that there is interference between the transmitting antenna 1 and receiving antennas 2, 3 and 4. This implies there is no proper transfer of information between the transmitting and receiving antennas. The mutual coupling values recorded at the frequency of $5.53 \mathrm{GHz}$ are $-16.95,-14.22$ and $-17.30 \mathrm{~dB}$ respectively in the order as states before. A value of mutual coupling greater than $-20 \mathrm{~dB}$ explains a severe level of interference between the transmitting antenna 1 and receiving antennas 2, 3 and 4. Figs. 6 and 7 show the fabricated CAA.

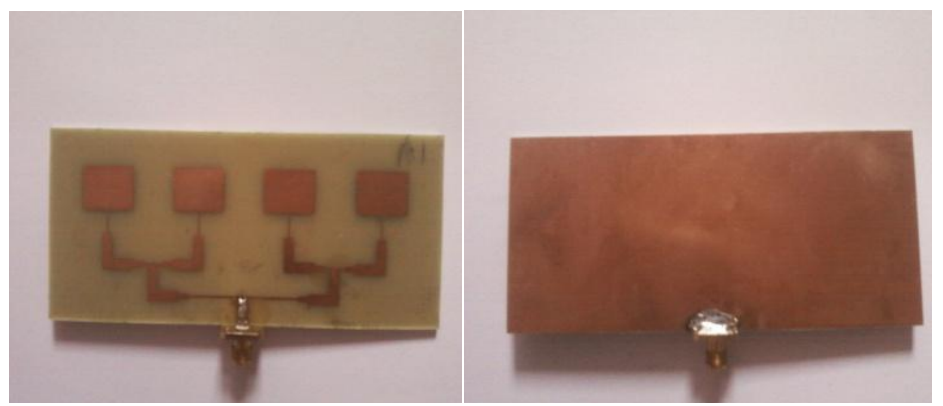

Fig.6. Photograph of four element antenna array.

(a) Front view

(b) Back view.

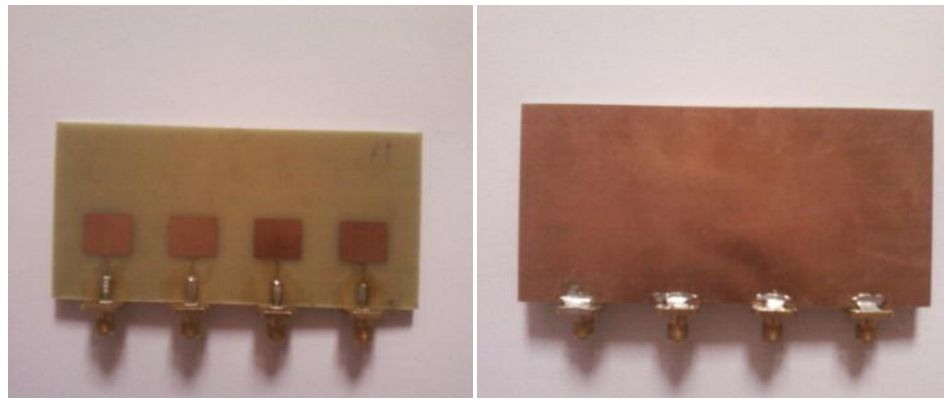

Fig.7. Photograph of four element antenna array for mutual coupling measurement.
(a) Front view
(b) Back view 
UGC Approved Journal

IJIREEICE

\section{International Journal of Innovative Research in} Electrical, Electronics, Instrumentation and Control Engineering

ISO 3297:2007 Certified

Vol. 5, Issue 6, June 2017

\section{ELECTROMAGNETIC BAND GAP STRUCTURE}

The EBG structure is now incorporated in the ground plane of CAA to examine the variation of performance of CAA without and with EBG structure. The unit cell of the EBG structure employed is shown in Fig.8. The dimensions of the unit cell are $A=9 \mathrm{~mm}, \mathrm{~B}=2 \mathrm{~mm}$ and $\mathrm{C}=2.75 \mathrm{~mm}$ respectively.

The EBG structure is now incorporated in the ground plane of CAA to examine the variation of performance of CAA without and with EBG structure. The unit cell of the EBG structure employed is shown in Fig.8. The dimensions of the unit cell are $\mathrm{A}=9 \mathrm{~mm}, \mathrm{~B}=2 \mathrm{~mm}$ and $\mathrm{C}=2.75 \mathrm{~mm}$ respectively.

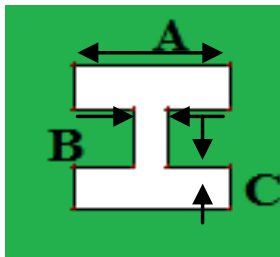

Fig.8. Unit cell of the EBG structure

The EBG structure consists of periodically placed I-shape slot arranged in the form of a matrix of 4 rows and 9 columns. The unit cells are repeated after every $5 \mathrm{~mm}$ along the $\mathrm{x}$-axis and y-axis. Fig.9 depicts the I-shape slot EBG structure.

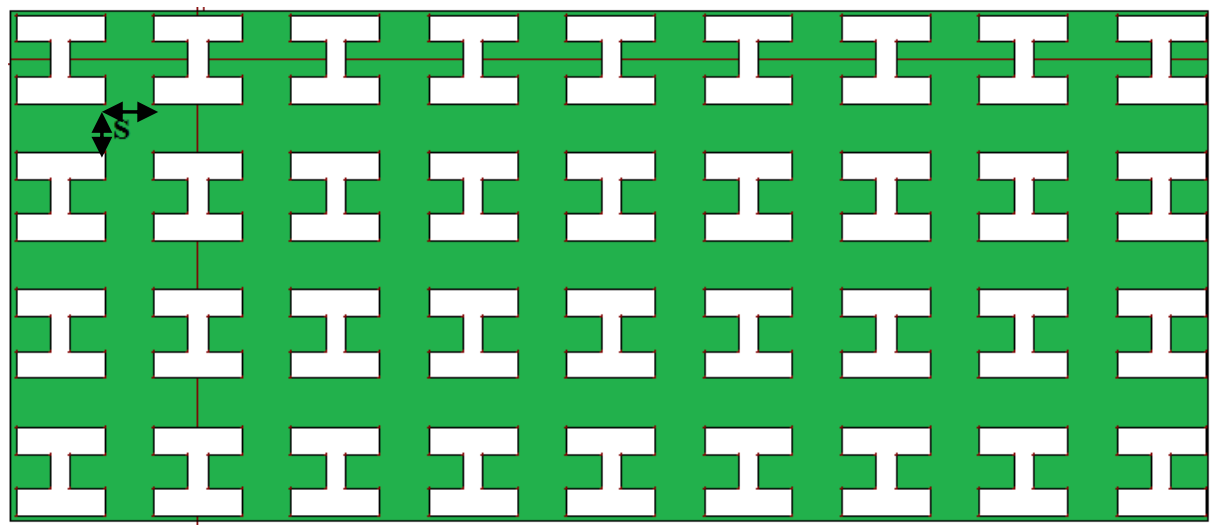

Fig.9. I-shape EBG structure

\section{IV.MODIFIED ARRAY ANTENNA CONFIGURATION}

EBG structures are a possible solution to tackle the limitations faced by the Microstrip array antennas. With the CAA loaded with the I-shape EBG structure in the ground plane, the array antenna showed considerable improvement in terms of various parameters. The schematic of the modified array antenna is depicted in Figs. 10 and 11.

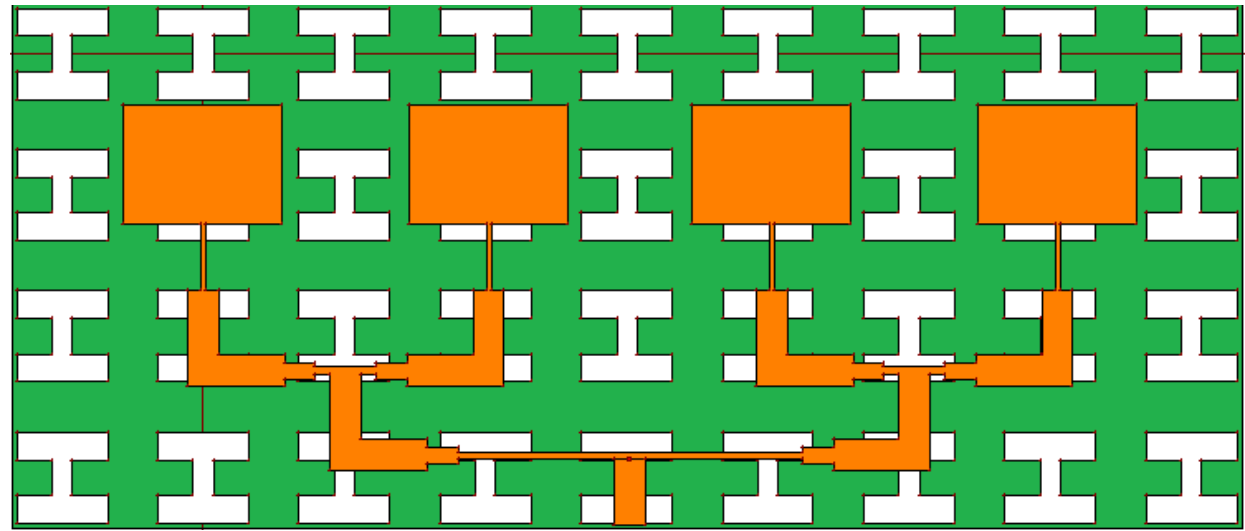

Fig.10.Schematic of conventional four element array antenna with EBG structure 
UGC Approved Journal

IJIREEICE

Vol. 5, Issue 6, June 2017

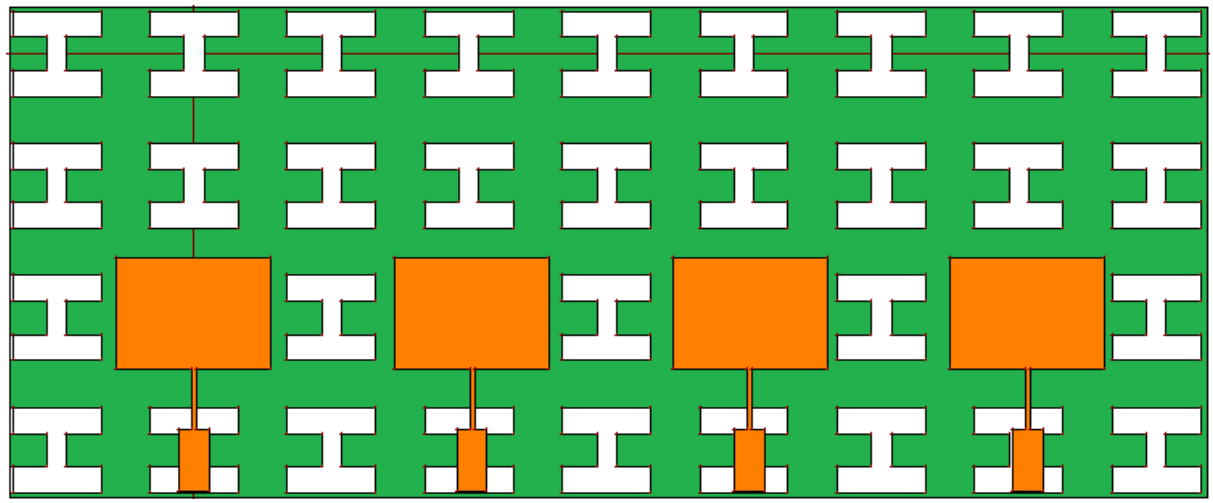

Fig.11.Schematic of conventional four element array antenna with EBG structure for mutual coupling measurement

From Figs. 12, 13 and 14 we see that the array antenna with I-shape EBG structure is resonating at 3.87, 5.53 and 6.74 $\mathrm{GHz}$ respectively (as depicted by the return loss plot).

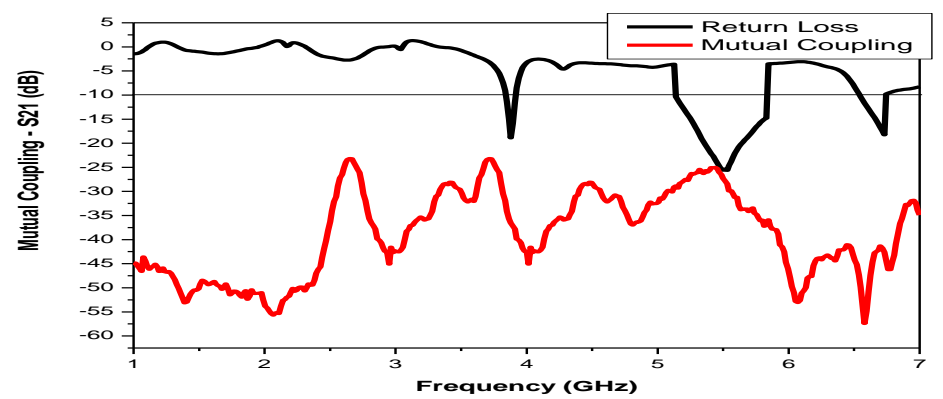

Fig.12. Plot of return loss and mutual coupling $-S_{21}$ versus frequency of CAA with I-shape EBG structure.

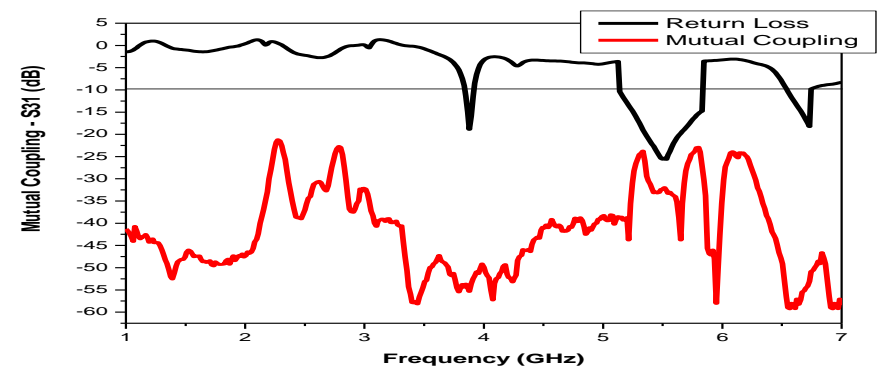

Fig.13. Plot of return loss and mutual coupling $-\mathrm{S}_{31}$ versus frequency of CAA with I-shape EBG structure.

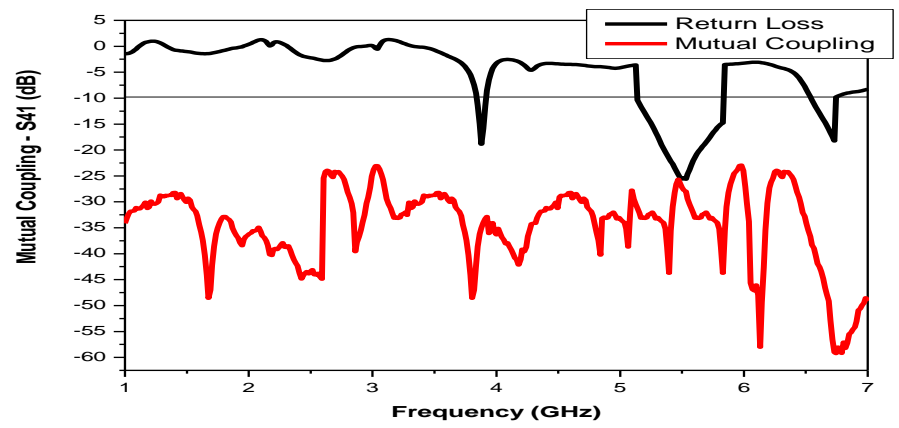

Fig.14. Plot of return loss and mutual coupling $-\mathrm{S}_{41}$ versus frequency of CAA.

The bandwidths measured at these resonant frequencies are 110, 740 and $220 \mathrm{MHz}$ respectively. Moreover, the mutual coupling measured at the frequency of $5.53 \mathrm{GHz}-27.97,-28.44$ and $-32.61 \mathrm{~dB}$ respectively. The mutual coupling values are reduced considerably by integrating the I-shape EBG structure with CAA. Additionally, the return loss and 
UGC Approved Journal

IJIREEICE

the mutual coupling plots are not overlapping at the frequency of $5.53 \mathrm{GHz}$, which implies the interference between the transmitting and receiving antennas has been reduced. Now there is better transfer of information as compared to in the former case. The overall bandwidth (\%) of CAA with the EBG structure is $19.48 \%$ as compared to $4.89 \%$ of conventional array antenna.

The modified array antenna is resonating at a fundamental resonant frequency of $3.87 \mathrm{GHz}$ as compared to $5.53 \mathrm{GHz}$. This corresponds to a virtual size reduction of $30.01 \%$.

In order to study the radiation characteristics of the array antenna, the E-plane radiation pattern of the array antenna is studied without and with I-shape EBG structure. The radiation plot provides information about the amount of power radiated by the antenna in the free space from $0^{\circ}$ to $360^{\circ}$. Fig. 15 depicts the radiation plot of CAA without and with EBG structure.

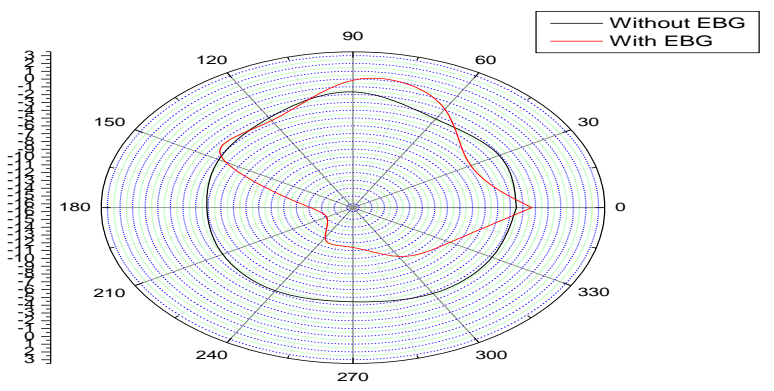

Fig.15. Plot of radiation pattern of four element array antenna without and with EBG structure.

At the angle of $90^{\circ}$, the amount of forward power radiated is more with EBG than that without EBG structure. The respective powers are 0 and $-2 \mathrm{~dB}$. At the angle of $270^{\circ}$, the amount of backward power radiated is decreased with the introduction of EBG structure. The amount of backward power radiated in the absence of EBG is $-5 \mathrm{~dB}$. The corresponding power with the introduction of EBG is reduced to $-11.5 \mathrm{~dB}$.

The front to back ratio (FBR) is calculated by subtracting the backward power from the forward power. The FBR without and with EBG structure are 5 and $9.5 \mathrm{~dB}$ respectively. Greater the FBR value better is the performance of the array antenna as more power is being radiated in the desired direction and lesser power in the backward direction.

The fabricated array antenna with I-shape EBG structure integrated is shown in Figs. 16 and 17.

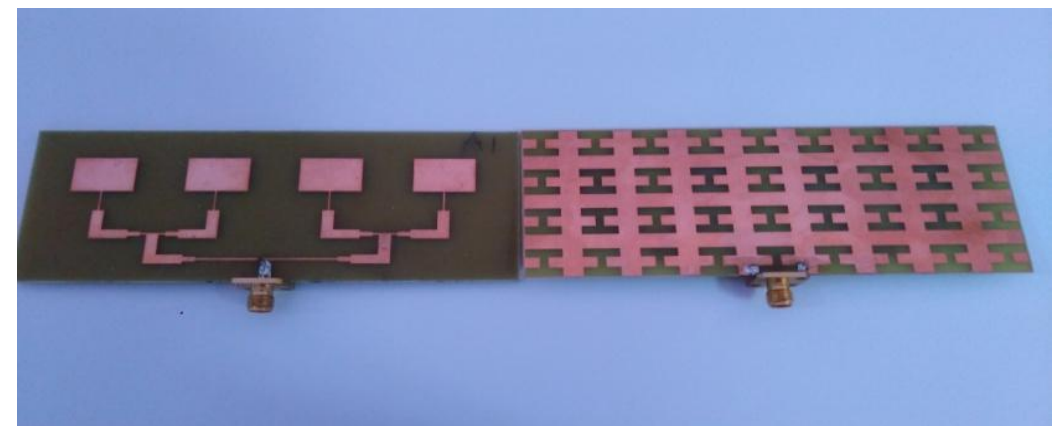

Fig.16. Photograph of conventional array antenna with I-shape EBG structure.

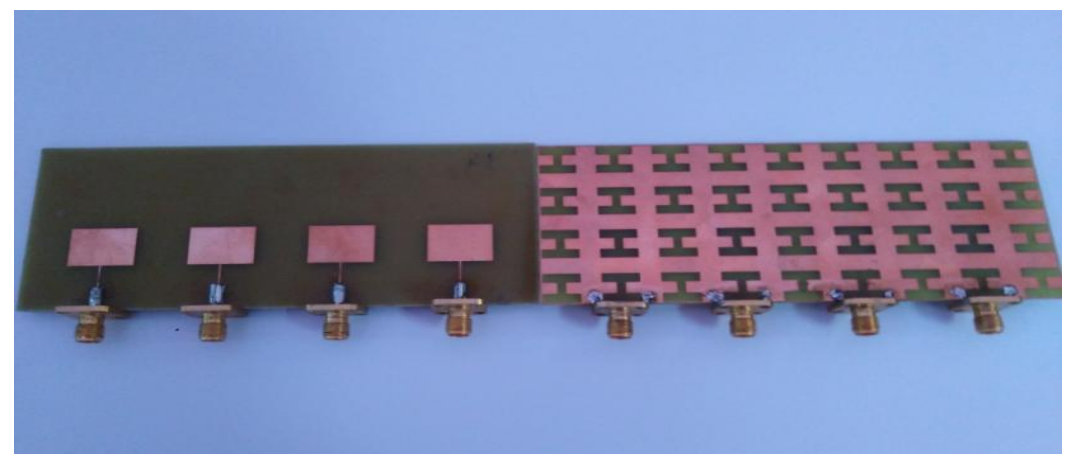

Fig.17. Photograph of conventional array antenna with I-shape EBG structure for mutual coupling measurement. 
UGC Approved Journal

IJIREEICE

\section{International Journal of Innovative Research in} Electrical, Electronics, Instrumentation and Control Engineering

\section{ISO 3297:2007 Certified}

Vol. 5, Issue 6, June 2017

Table 2. Summarized measured results.

\begin{tabular}{|c|c|c|c|c|c|}
\hline $\begin{array}{c}\text { Type of } \\
\text { Antenna }\end{array}$ & $\begin{array}{c}\text { Resonant } \\
\text { Frequency }(\mathrm{GHz})\end{array}$ & $\begin{array}{c}\text { Return Loss } \\
(\mathrm{dB})\end{array}$ & $\begin{array}{c}\text { Band Width } \\
(\mathrm{MHz})\end{array}$ & $\begin{array}{c}\text { Overall Band } \\
\text { Width }(\%)\end{array}$ & $\begin{array}{l}\text { Front to Back } \\
\text { Ratio }(\mathrm{dB})\end{array}$ \\
\hline Without EBG & 5.53 & -21.06 & 273 & 4.89 & 5 \\
\hline With I-shape slot & 3.87 & -18.83 & 110 & & \\
EBG structure & 5.53 & -25.41 & 740 & 19.48 & 9.5 \\
\hline
\end{tabular}

Table 3. Summarized measured results of mutual coupling.

\begin{tabular}{|c|c|c|c|}
\hline Type of Antenna & $\begin{array}{c}\text { Mutual } \\
\text { Coupling }-\mathrm{S}_{21}(\mathrm{~dB})\end{array}$ & $\begin{array}{c}\text { Mutual } \\
\text { Coupling }-\mathrm{S}_{31}(\mathrm{~dB})\end{array}$ & $\begin{array}{c}\text { Mutual } \\
\text { Coupling }-\mathrm{S}_{41}(\mathrm{~dB})\end{array}$ \\
\hline Without EBG & -16.95 & -14.22 & -17.30 \\
\hline With I Shape Slot EBG & -27.97 & -28.44 & -32.61 \\
\hline
\end{tabular}

\section{CONCLUSION}

In this paper the performance of four element array antenna with EBG structure is compared with that of the conventional array antenna. With the introduction of two dimensional I-shape EBG structure in the ground plane, the four element array antenna has shown good improvement in the performance characteristics. The modified array antenna is resonating at three different frequencies providing an overall bandwidth of $19.48 \%$. Miniaturization of array antenna of $30.01 \%$ has been produced with a good reduction in mutual coupling. The radiation characteristics of the array antenna have also been improved.

\section{REFERENCES}

[1] Constantine A Balanis; Antenna Theory, Analysis and Design, John Wiley \& Sons Inc $2^{\text {nd }}$ edition.1997.

[2] I. J. Bahl and P. Bhartia, Microstrip Antennas, Artech House, 1980.

[3] Prof James Scott; Lecture notes of EEET1071/1127 Microwave and Wireless Passive Circuit Design.

[4] Fan Yang and Yahya Rahmat-Samii, "Electromagnetic Band Gap Structures in Antenna Engineering, Cambridge University Press, 2009.

[5] D. N. Elsheakh, E. A. Abdallah, M. F. Iskander and H. A. Elsadek, "Microstrip Antenna Array with New 2D-Electromagnetic Band Gap Structure Shapes to Reduce Harmonics and Mutual Coupling", Progress in Electromagnetic Research C, Vol.12,pp.203-213,2010.

[6] F. Benikhelf and N.Boulki-Hacene, "Mutual Coupling Reduction in Patch Antenna Arrays Using EBG Structures", International Journal of Computer Science Issues, Vol.09, Issue. 04, pp.265-269, Jul 2012

[7] Foram N. Dharsandiya and Ila D. Parmar, "Optimization of Antenna Design for Gain Enhancement Using Array", International Journal of Advanced Research in Computer Science and Software Engineering, Vol.04, Issue. 01, pp.1038-1043, Jan 2014.

[8] Hamideh Kondori, Mohammad Ali Mansouri- Birjandi and Saeed Tavakoli, "Reducing Mutual Coupling in Microstrip Array Antenna Using Metamaterial Spiral Resonator”, International Journal of Computer Science Issues, Vol.09, Issue. 03, pp.51-56, May 2012.

[9] R.Dhanalakshmi, Santosh Kumar and R.Srinivas, "Reducing Mutual Coupling in Microstrip Array Antenna Using Metamaterial Spiral Resonator”, International Journal of Computer Science Issues, Vol.09, Issue. 03, pp.51-56, May 2012.

[10] Q.Rong Zheng, Y.Fu, and N.Chang Yuan, "A Novel Compact Spiral Electromagnetic Band-Gap (EBG) Structure", IEEE transactions on antennas and propagation, vol. 56, pp.1656-1650 June 2008.

[11] T.Masri, M.K.A.Rahim and M.N.A.Karim, "A Novel 2D Sierpinski Gasket Electromagnetic Band Gap Structure for Multiband Microstrip Antenna", Proc. of ISAP 2007, Niigata, Japan.

[12] Yahya S.H.Khraisat, "Design of 4 Elements Rectangular Microstrip Patch Antenna with High Gain for 2.4 GHz Applications", Journal of Modern Applied Science, Vol.06, Issue.01, pp.68-74, Jan 2012.

[13] Vibha Gajway, "Design of Circularly Polarized Broadband Microstrip Patch Array Antenna using HFSS for WLAN Application", European Journal of Advances in Engineering and Technology, pp.18-22, 2015.

[14] A.De, C.K.Chosh and A.K.Bhattacherjee, "Design and Performance Analysis of Microstrip Patch Array Antennas with different configurations", International Journal of Future Generation Communication and Networking, Vol.09, Issue.03, pp.97-110, 2016. 